\title{
Prevalence of iodine deficiency disorders among school children in Saudi Arabia: results of a national iodine nutrition study
}

M.H. Al-Dakheel, ${ }^{1}$ H.K. Haridi, ${ }^{1}$ B.M. Al-Bashir, ${ }^{1}$ A. Al-Shingiti, ${ }^{1}$ S. Al-Shehri, ${ }^{2}$ M.A. Gassem ${ }^{3}$ and I. Hussein ${ }^{4,5}$

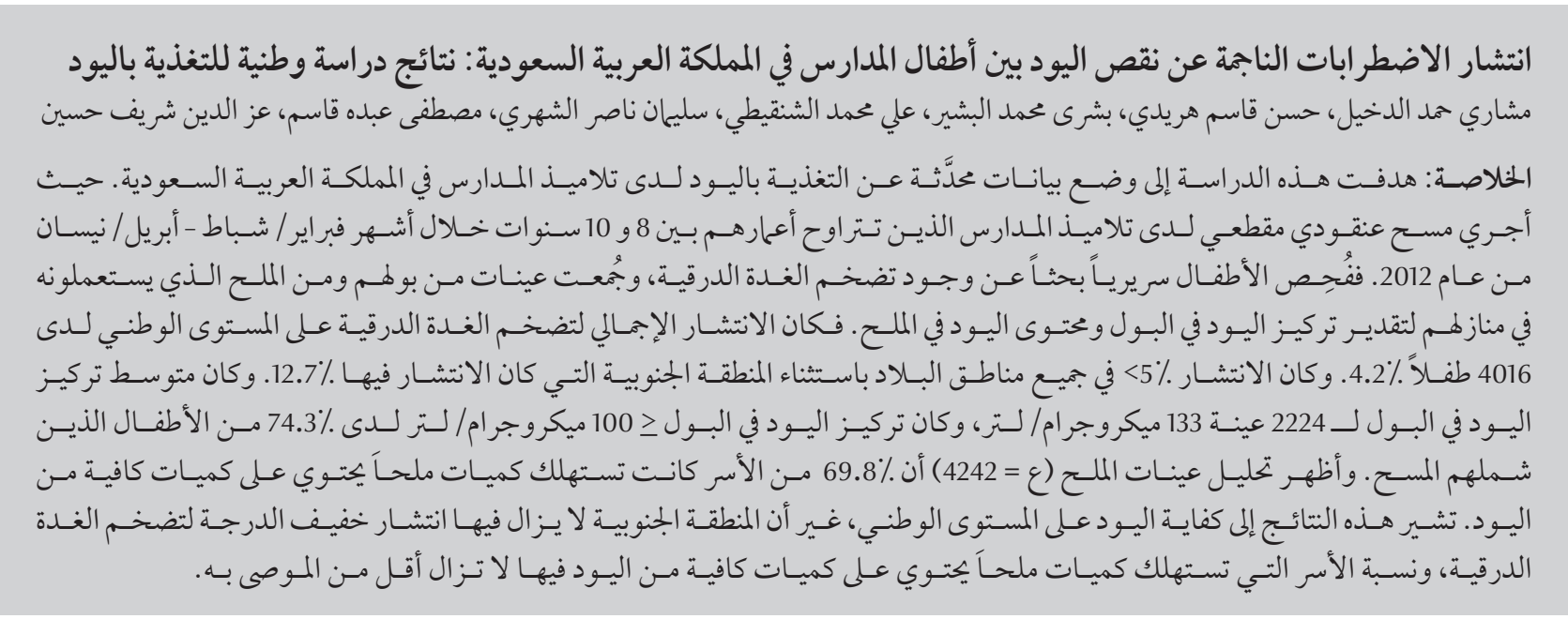

ABSTRACT This study aimed at establishing updated data on iodine nutrition among schoolchildren in Saudi Arabia. A cross-sectional cluster survey among schoolchildren aged 8-10 years was conducted during February-April 2012. Children were clinically examined for goitre, urine and household salt samples were collected to estimate urinary iodine concenteration (UIC) and iodine content in salt. The overall goitre prevalence at the national level among 4016 children was $4.2 \%$. The prevalence was $<5 \%$ in all regions of the country except southern region with a prevalence of $12.7 \%$. The median UIC of 2224 samples was $133 \mu \mathrm{g} / \mathrm{L}$, with $74.3 \%$ of the surveyed children with UIC $\geq 100 \mu \mathrm{g} / \mathrm{L}$. Analysis of salt samples $(n=4242)$ revealed that $69.8 \%$ of households were consuming adequately iodized salt. The findings suggest iodine sufficiency at the national level, however southern region still has a goitre prevalence of mild degree severity and the proportion of households consuming adequately iodized salt is still below recommendations.

Prévalence des troubles dus à une carence en iode parmi les enfants d'âge scolaire en Arabie saoudite : résultats d'une étude nationale sur la nutrition en iode

RÉSUMÉ Cette étude visait à recueillir des données mises à jour sur la nutrition en iode parmi les enfants d'âge scolaire en Arabie saoudite. Une étude transversale par sondage en grappes a été menée auprès enfants d'âge scolaire âgés de 8 à 10 ans entre février et avril 2012. Les enfants ont été soumis à un examen clinique pour le goître, et des échantillons d'urine et de sel de cuisine ont été collectés afin d'estimer la concentration d'iode urinaire et la teneur en iode dans le sel. La prévalence globale du goître au niveau national parmi les 4016 enfants était de 4,2 \%. La prévalence était inférieure à $5 \%$ dans l'ensemble des régions du pays, exception faite de la partie sud qui présentait une prévalence de $12,7 \%$. La concentration médiane d'iode urinaire de 2224 échantillons était de $133 \mu \mathrm{g} / \mathrm{L}, 74,3 \%$ des enfants examinés ayant une concentration d'iode urinaire inférieure ou égale à $100 \mu \mathrm{g} / \mathrm{L}$. Les proportions d'enfants ayant des taux de concentration d'iode urinaire inférieurs à 20, compris entre 20 et 49 et 50 et $99 \mu \mathrm{g} / \mathrm{L}$, étaient de 2,0 \%, 5,3\% et 18,5\% respectivement. L'analyse des échantillons de sel $(n=4242)$ a révélé que $69,8 \%$ des ménages consommaient du sel adéquatement iodé. Les résultats suggèrent un niveau de consommation en iode suffisant à l'échelle nationale, bien que la partie sud du pays continue d'avoir une prévalence du goître de sévérité moyenne, et que la proportion des ménages consommant du sel adéquatement iodé reste en deçà des recommandations.

'Ministry of Health, Riyadh, Saudi Arabia (Correspondence to: H.K. Haridi: hassankasim@hotmail.com). ${ }^{2}$ Ministry of Education, Riyadh, Saudi Arabia. ${ }^{3}$ Saudi Food and Drug Authority, Riyadh, Saudi Arabia. ${ }^{4}$ Lipidomics and Nutrition Research Centre, London Metropolitan University, London, UK. ${ }^{5}$ lodine Global Network (IGN), Zurich, Switzerland.

Received: 27/07/15; accepted: 27/03/16 


\section{Introduction}

Iodine is an essential micronutrient and its deficiency has several adverse effects on growth and development because of inadequate thyroid hormone production (1). Iodine deficiency disorder (IDD) refers to all the effects of iodine deficiency on growth and development that can be prevented by correction of the deficiency (2). Most consequences of IDD are invisible and irreversible but at the same time preventable. The World Health Organization (WHO) describes iodine deficiency as "the single most important preventable cause of brain damage" (3). Even in developed countries, marginal iodine sufficiency may lead to intellectual compromise (4). Worldwide, $\sim 30 \%$ of school-aged children were iodine deficient in 2011 (5).

IDD results from insufficient iodine in the environment and inadequate iodine intake from food (6). Salt iodization as a safe, cost-effective and sustainable strategy to ensure sufficient iodine intake was recommended by WHO and United Nations Children's Fund (UNICEF) in 1994 (7). It is now recognized that the most effective way to achieve the virtual elimination of IDD is through universal salt iodization (USI) (8). Many countries and $71 \%$ of the world's population are estimated to be covered by iodized salt ( 8 ).

The only national survey to assess iodine status in Saudi Arabia was carried out in 1994-1995 $(9,10)$. The national median urinary iodine concentration (UIC) was $180 \mu \mathrm{g} / \mathrm{L}$ and the prevalence of goitre ranged between $4 \%$ in an urban costal community to $30 \%$ in the high-altitude Asir Region. The study recommended adoption of a USI strategy. Taking into consideration the outcomes of the study, the Saudi Standards Metrology and Quality Organization recommended an iodine content in salt of $70-100 \mathrm{ppm}$. Following the WHO/ UNICEF/International Council for the Control of Iodine Deficiency Disorders
(ICCIDD) guidelines, the range of the recommended fortification level was changed to 15-40 ppm in 2010 (11).

A survey report in Hail Region, in the north of Saudi Arabia, in 2004, revealed that less than one-third of families were using iodized salt as the main source of salt (12). In contrast, a study in Jizan in 2010 reported that almost all households were consuming iodized salt (13).

Since the first national survey in 1994-1995, sociocultural and economic development, urbanization, changes in dietary habits and lifestyle, as well as adoption of USI strategies, have potentially had an effect on iodine nutrition in Saudi Arabia. Therefore, this study aimed to establish updated national data on goitre prevalence and median UIC and to assess the proportion of households consuming adequately iodized salt.

\section{Methods}

\section{Study setting \& design}

Saudi Arabia is a large country that encompasses $80 \%$ of the Arabian Peninsula with an area of nearly 2 million $\mathrm{km}^{2}$. The land is primarily desert with rugged mountains in the south-west. The country is broadly divided into five geographical/administrative territorial entities: central, eastern, western, northern and southern regions with 13 primary subdivisions. The estimated population according to the 2010 census was $\sim 27$ million (14).

The study was cross-sectional national survey among primary-school children aged $8-10$ years, based on the 30 cluster sampling methodology recommended by WHO/UNICEF/ $\operatorname{ICCIDD}(15)$.

\section{Study participants \& sampling}

The sampling frame of the study included all 13626 primary schools in Saudi Arabia (public and private), representing the primary sampling units
(16). For good regional representation, the country was stratified into the five geographical regions. Using a probability proportionate to size sampling method, 30 clusters were drawn randomly from the primary sampling units in each region (15). A comprehensive list of all children in the target age group was prepared for each selected school. Children were chosen at random by a systematic random technique to include the total number needed from each school. Twenty-six children per cluster was estimated for a sample size of 780 children for every region. An absolute precision of $\pm 3 \%$ with $95 \%$ confidence interval (CI) and design effect of 2 for anticipated $10 \%$ goitre prevalence were the assumptions for sample size estimation (15). Sample size was then increased by $10 \%$ to compensate for non-response. The anticipated goitre prevalence was decided with reference to pervious national and local studies $(9,17)$.

A total of 4311 school children ( $52.2 \%$ male and $47.8 \%$ female) aged 8-10 years participated in the study, with $31.8 \%, 36.7 \%$ and $31.6 \%$ aged 8,9 and 10 years respectively.

\section{Data collection}

Data on participants' age, gender, educational class and locality were collected. All children were examined for goitre. Clinical examination of the thyroid was performed by physicians who had undergone training in goitre palpation. Goitre classification was according to the criteria recommended by $\mathrm{WHO} /$ UNICEF/ICCIDD as Grade 0, 1 or 2. The sum of Grades 1 and 2 provided the total goitre rate (TGR) (2).

Casual urine samples were collected from a random subsample of 50\%, selected systematically to provide urine for estimation of UIC. Urine samples were collected in sterile disposable cups and transferred into sealed $10-\mathrm{mL}$ tubes. Samples were transported to the Central Laboratory for Nutrition in Riyadh and stored at $-18^{\circ} \mathrm{C}$ until analysis. 
The ammonium persulfate method described by Dunn et al. was used for measuring iodine in urine (18). Classification of the severity of IDD was according to WHO cut-off points of $\operatorname{UIC}(2)$.

Samples of $\sim 20 \mathrm{~g}$ of routinely consumed salt were collected by requesting all participants to bring them from their homes. Each sample was screened for iodine content using a rapid test kit (RTK). Twenty-five percent of the iodated salt samples screened by RTK were randomly selected for iodine level determination using an iodometric titration method (2). All salt analysis were done centrally under quality control measures in the Central Laboratory for Nutrition in Riyadh.

\section{Training and survey technique}

To collect valid, standardized survey data, 3 training workshops, including field training, were carried out for the recruited physicians, nurses and health inspectors. Physicians were assigned to examine thyroid size clinically; nurses for collection of urine and salt samples; and health inspectors for coordinating school visits and obtaining a list of the eligible target students. Training emphasized standardization of thyroid gland examination and goitre grading system according to the WHO/UNICEF/ ICCIDD guidelines, and urine and salt sample collection, storage and transportation (2).

\section{Statistical analysis}

Data processing and statistical analyses were performed using Epi Info version 3.5.4 statistical package (Centers for Disease Control and Prevention, Atlanta, GA, USA).

As the continuous variable of UIC was not normally distributed, the results were described as median and percentiles and the differences were evaluated by the nonparametric Kruskal-Wallis $H$ test and Mann-Whitney Utest as appropriate. Other continuous variables were expressed as mean and standard deviation (SD). Categorical data were summarized by frequencies and percentage. The percentage and 95\% CI for goitre and household iodized salt consumption were calculated. The $\chi^{2}$ test was used to test for differences in proportions. Effect size was expressed as odds ratio (OR) and 95\% CI. National estimates were adjusted according to the total number of children per region compared to the national total. Analysis for complex sampling design took into consideration sampling stratification, clustering and regional weights and permitting estimates adjustment. All tests were two-sided and the level of significance was set at $P<0.05$.

\section{Ethical considerations}

The ethical issues of this study were reviewed and approved by the Ethical Committee of the Ministry of Health, Saudi Arabia. Approval was also obtained from the Education Authority.
Written informed consent was obtained from the parents/guardians of participating children.

\section{Results}

\section{Prevalence of goitre}

Complete data for goitre were obtained for 4016 children with no significant differences compared with the number of total participants with regard to gender $(P=0.193)$, age $(P=0.237)$ or educational class $(P=0.323)$. TGR at the national level was $4.2 \%$ (95\% CI: $3.9-4.5 \%)$; 3.6\% for Grade 1 and $0.6 \%$ for Grade 2 (Table 1). The prevalence was $<5 \%$ in all parts of the country except the southern region, which scored $12.7 \% ; 10.8 \%$ for Grade 1 and 1.8\% for Grade 2 (Table 1). TGR was significantly higher in girls (7.1\%) than boys (3.1\%) (OR: 2.4; 95\% CI :1.8-3.3\%; P $<0.001)$, but no age-related difference was found $(P=0.431)$.

\section{Urinary iodine}

The median UIC at national level was found to be $133 \mu \mathrm{g} / \mathrm{L}$ (20-80th percentile: $88-167 \mu \mathrm{g} / \mathrm{L})$ and scored > $100 \mu \mathrm{g} / \mathrm{L}$ in all regions of the country (Table 2). The highest level (157 $\mu \mathrm{g} / \mathrm{L})$ was observed in the eastern region and the lowest $(119 \mu \mathrm{g} / \mathrm{L})$ in the southern region (Table 2). The difference in median UIC between regions was significant $(P<0.001)$. About three quarters (74.3\%) of children at the national level

\begin{tabular}{|c|c|c|c|c|c|}
\hline \multirow[t]{2}{*}{ Region } & \multirow[t]{2}{*}{ No. examined } & \multicolumn{4}{|c|}{$\%$ children according to grade of goitre } \\
\hline & & Grade 0 & Grade 1 & Grade 2 & TGR $(95 \% \mathrm{Cl})$ \\
\hline Central & 945 & 95.9 & 3.0 & 1.1 & $4.1(3.9-4.4)$ \\
\hline Western & 872 & 96.6 & 3.3 & 0.1 & $3.4(3.7-4.1)$ \\
\hline Eastern & 785 & 98.1 & 1.8 & 0.1 & $1.9(1.7-2.2)$ \\
\hline Northern & 768 & 95.2 & 4.6 & 0.3 & $4.9(4.3-5.4)$ \\
\hline Southern & 646 & 87.3 & 10.8 & 1.8 & $12.7(12.5-13.8)$ \\
\hline National ${ }^{\mathrm{a}}$ & 4016 & 95.8 & 3.6 & 0.6 & $4.2(3.9-4.5)$ \\
\hline
\end{tabular}

${ }^{a}$ Adjusted according to total number of children per region compared to the national total.

There was a significant difference of TGR between regions $\left(\chi^{2}=105.1 ; d f=4 ; P<0.001\right)$.

$\mathrm{Cl}=$ confidence interval; $T G R=$ total goitre rate. 


\begin{tabular}{|c|c|c|c|c|}
\hline Region & No. examined & $\begin{array}{l}\text { Median }^{\mathrm{a}}\left(20^{-} 80 \text { th }\right. \\
\text { percentiles })\end{array}$ & Mean (SD) & $\begin{array}{c}\% \text { participants with median UIC }< \\
\qquad 100 \mu \mathrm{g} / \mathrm{L}\end{array}$ \\
\hline Central & 470 & $123(75-152)$ & $116.9(45.3)$ & 32.8 \\
\hline Western & 491 & 138 (91-170) & $129.9(45.8)$ & 25.3 \\
\hline Eastern & 408 & 157 (106-194) & $149.8(57.2)$ & 14.7 \\
\hline Northern & 495 & 134 (90-166) & $127.7(45.2)$ & 22.7 \\
\hline Southern & 360 & 119 (78-155) & $117.1(43.3)$ & 24.3 \\
\hline National $^{\mathrm{b}}$ & 2224 & $133(88-167)$ & $128.2(48.2)$ & 25.8 \\
\hline
\end{tabular}

${ }^{a}$ Normal range $=100-199 \mu \mathrm{g} / \mathrm{L}$.

${ }^{b}$ Adjusted according to total number of children per region compared to national total.

There was a significant difference in median UIC among regions (Kruskal-Wallis H test; $\chi^{2}=79.0 ; d f=4 ; P<0.001$ ).

$S D=$ standard deviation; $U I C=$ urinary iodine concentration

had optimal iodine nutrition (UIC $\geq$ $100 \mu \mathrm{g} / \mathrm{L})$. Mild, moderate and severe IDD were found in $18.5 \%, 5.2 \%$ and $2.0 \%$ of children respectively, with significant differences among the regions $(P<0.001)($ Table 3). No children had median UIC $>300 \mu \mathrm{g} / \mathrm{L}$ (excessive iodine intake). Median UIC did not differ significantly with regard to gender $(P=0.887)$ or age $(P=0.623)$.

TGR among iodine-sufficient participants (UIC $>100 \mu \mathrm{g} / \mathrm{L}$ ) was $3.5 \%$ compared to $8.6 \%$ among iodine-deficient participants (UIC $<100 \mu \mathrm{g} / \mathrm{L}$ ), with a significantly reduced risk of goitre among iodine-sufficient participants $(\mathrm{OR}=0.39,95 \%$ CI: 0.24-0.63; $P<$
0.001). Figure 1 depicts the significant inverse relationship between UIC and prevalence of goitre $\left(\chi^{2}=31.9, \mathrm{df}=3 ; P\right.$ $<0.001)$.

\section{lodine content of salt}

Among the 4242 salt samples collected, 68.7\% (95\% CI: $67.3-70.1 \%)$ were found to be iodized using the RTK (Table 4), with significant regional differences $(P<0.001)$. The northern region had the lowest number (53.8\%) of iodized salt samples and the western region had the highest $(80.6 \%)$. We tested 775 representative iodized salt samples using iodometric titration methods for validation of salt samples that tested positive for iodine with the RTK. The results revealed adequate ( $\geq 15 \mathrm{ppm}$ ) iodine content in salt in 95.2\% (95\% CI: 93.9-96.5) of the samples, with a mean 50.4 (SD 21.8) and median $51 \mathrm{ppm}$ concentration. The national weighted estimate of the proportion of households consuming adequately iodized salt was $69.8 \%$. An obvious relationship was noticed between household consumption of iodized salt and both goitre prevalence and median UIC. A significant inverse relationship $(P=0.038)$ was found in relation to goitre prevalence and a positive relationship $(P<0.001)$ with median UIC.

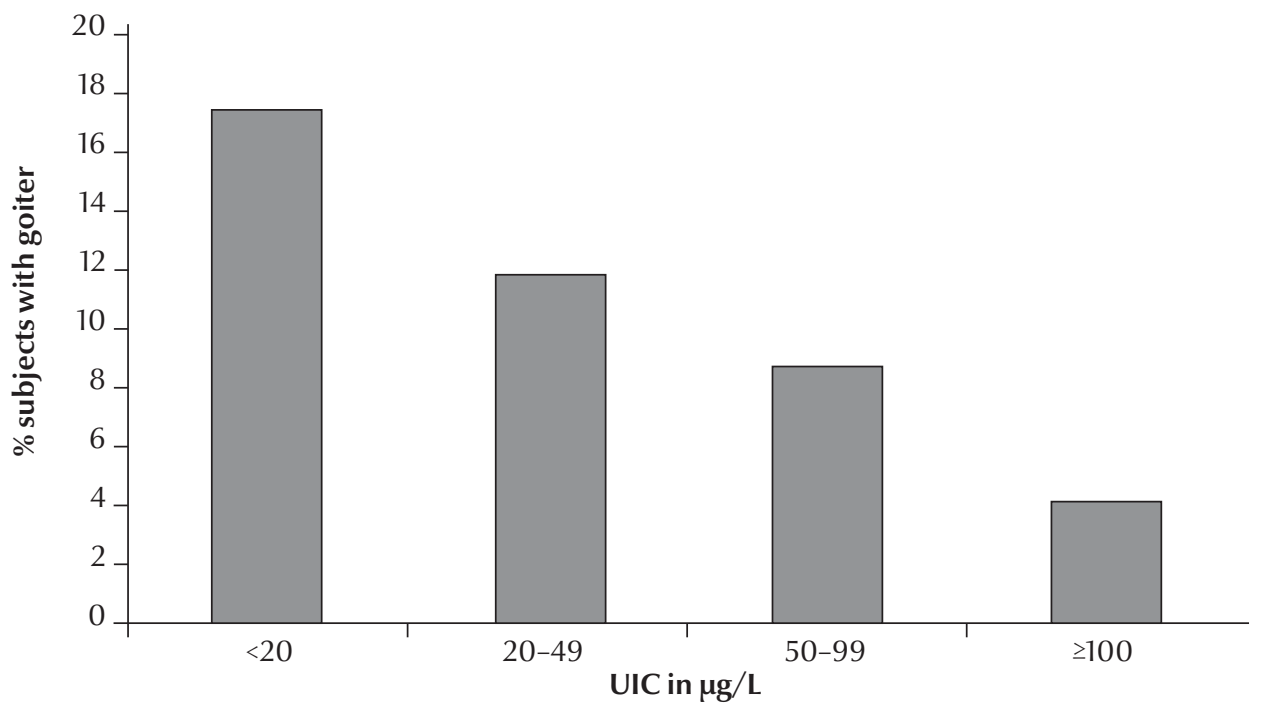

Figure 1 Prevalence of goitre among participants with different UICs $\left(\chi^{2}=31.9 ; \mathrm{df}=3 ; \boldsymbol{P}<0.001\right)(\mathrm{UIC}=$ urinary iodine concentration). 


\begin{tabular}{|c|c|c|c|c|c|c|c|}
\hline \multirow[t]{2}{*}{ Region } & \multirow{2}{*}{$\begin{array}{c}\text { No. } \\
\text { examined }\end{array}$} & \multicolumn{6}{|c|}{$\%$ children according to range of Median UIC $(\mu \mathrm{g} / \mathrm{L})^{\mathrm{a}}$} \\
\hline & & $<\mathbf{2 0}$ & $20-49$ & $50-99$ & 100-199 & 200-299 & $\geq 300$ \\
\hline Central & 470 & 2.7 & 6.9 & 23.2 & 64.8 & 2.4 & 0 \\
\hline Western & 491 & 2.0 & 4.1 & 19.2 & 72.9 & 1.8 & 0 \\
\hline Eastern & 408 & 1.2 & 4.7 & 8.8 & 66.9 & 18.4 & 0 \\
\hline Northern & 495 & 1.2 & 6.1 & 15.3 & 75.3 & 2.0 & 0 \\
\hline Southern & 360 & 1.7 & 4.7 & 17.9 & 75.8 & 0 & 0 \\
\hline National $^{\mathrm{b}}$ & 2224 & 2.0 & 5.2 & 18.5 & 70.0 & 4.3 & 0 \\
\hline
\end{tabular}

${ }^{a}$ Normal range $=100-199 \mu \mathrm{g} / \mathrm{L}$

${ }^{b}$ Adjusted according to total number of children per region compared to national total.

There was a significant difference in UIC among regions ( $\left.\chi^{2}=52.8 ; d f=12 ; P<0.001\right)$.

UIC = urinary iodine concentration.

\section{Discussion}

Since the first national survey in 1994-1995, national data about IDD in Saudi Arabia have been lacking. There have been a few regional studies, mostly from the southern part of the country, with no information about household consumption of iodized salt; hence the importance of the present survey.

The median UIC and goitre prevalence observed in this study suggest iodine sufficiency in the Saudi Arabian population at the national level. They also substantiate the findings of the first national survey and indicate the sustainability of meeting the iodine nutritional needs of the population (2). Early studies indicated that iodine concentration in Saudi Arabian staple food contains adequate iodine (19). Upgraded studies are needed to describe and quantify different sources of iodine in the Saudi
Arabian diet and the pattern of consumption.

Based on WHO/ICCIDD/ UNICEF criteria, 2 primary criteria of sustainable elimination of IDD $(<50 \%$ of population with UIC $<100 \mu \mathrm{g} / \mathrm{L}$ and $<5 \%$ goitre prevalence) were met. However, efforts are still needed to reach the third criterion of $>90 \%$ of households consuming adequate iodized salt (2). The study also highlighted significant regional variations, especially in household consumption of iodized salt, and revealed a still higher goitre prevalence in the southern region despite 2 decades of USI.

\section{Goitre prevalence}

Goitre prevalence is an index of the degree of long-standing iodine deficiency. A prevalence of 5\% is taken as the maximum above which iodine deficiency is designated as a public health problem
(2). In the present study, an estimated TGR of $4.2 \%$ at the national level was below this margin and indicate a reduction of goitre prevalence compared to that reported in the first national survey (4-30\%) (9). Four regions out of 5 scored TGR $<5 \%$ and only the southern region was higher at $12.7 \%$ to be classified as a mild degree of severity according to $\mathrm{WHO}$ epidemiological criteria for establishing IDD severity, based on goitre prevalence in schoolchildren (2).

The southern region of Saudi Arabia is mostly high altitude and high goitre prevalence has been reported in previous studies $(9,13,17)$. High goitre prevalence is a characteristic of mountainous regions in other countries because of leached soil iodine $(6,20)$. In contrast, reflecting different ecological patterns, the coastal, nonmountainous the eastern and western regions in Saudi

\begin{tabular}{lccc}
\hline $\begin{array}{l}\text { Table } 4 \text { Proportion of households consuming adequately iodized salt, at the national and regional levels, Saudi Arabia, } 2012 \\
\text { Region }\end{array}$ & $\begin{array}{c}\text { \% (95\% Cl) iodized salt } \\
\text { screened by } \mathbf{R T K}\end{array}$ & $\begin{array}{c}\text { \% } \mathbf{( 9 5 \% ~ C l )} \text { adequately iodized } \\
\text { salt }^{\mathrm{a}}\end{array}$ \\
Central & 932 & $79.7(77.0-82.2)$ & $75.9(73.2-78.7)$ \\
Western & 968 & $80.6(77.9-83.0)$ & $76.7(74.0-79.4)$ \\
Eastern & 683 & $63.8(60.1-67.4)$ & $60.7(57.0-64.4)$ \\
Northern & 1042 & $53.8(50.8-56.9)$ & $51.2(48.2-54.2)$ \\
Southern & 617 & $64.0(60.1-67.8)$ & $60.9(57.1-64.8)$ \\
National & 4242 & $68.7^{\mathrm{b}}(67.3-70.1)$ & $69.8^{\mathrm{c}}(68.4-71.2)$ \\
\hline
\end{tabular}

${ }^{a}$ Validated by iodometric titration method at $95.2 \%$ of salt samples with iodine content $\geq 15 \mathrm{ppm}$.

${ }^{b}$ For total salt samples, unadjusted for national estimate.

${ }^{c}$ Adjusted for national estimate according to total number of children per region compared to national total.

There was a significant difference in iodized salt samples among regions $\left(\chi^{2}=237.1 ; d f=4 ; P<0.001\right)$.

$\mathrm{Cl}=$ confidence interval; $\mathrm{RTK}=$ rapid test $\mathrm{kit}$. 
Arabia appeared to have the lowest goitre prevalence of $1.9 \%$ and $3.4 \%$ respectively. These results confirm the findings of the first national survey (9).

Historically, few individual studies have estimated goitre prevalence among school-aged children. A prevalence of $0.9 \%$ among male children aged 6-15 years was found in Riyadh in 1988 (21); 24\% in Asir (2001) with higher levels in high altitude (27\%) than low altitude (13\%) areas (17), and a study in Jizan (2010) reported a prevalence of $11 \%(13)$.

Girls in the present study were at higher risk of developing goitre than boys were, which could be attributed to the increased physiological demand for iodine during puberty, which begins 2 years earlier in girls $(22,23)$. The higher goitre rate among girls was consistent with earlier observations (13). Compared to neighbouring countries, goitre prevalence in the present study was higher than in Bahrain (1.7\%) but lower than in Oman (10\%), Jordan (33.5\%) and Egypt (21.4\%) (24).

\section{Urinary iodine}

Urinary iodine level is used as a valuable indicator for the assessment of IDD because $90 \%$ of iodine in the body is excreted through urine. It is a sensitive indicator of recent changes in iodine intake and a median UIC of $100 \mu \mathrm{g} / \mathrm{L}$ indicates that there is no iodine deficiency in the population (2).

Within the optimal range, the national median UIC in the present survey $(133 \mu \mathrm{g} / \mathrm{L})$ was lower than $180 \mu \mathrm{g} / \mathrm{L}$ reported in the $1994-1995$ survey. This reduction could be attributed to the adjustment of salt iodine concentration in Saudi Arabia code from 70-100 ppm to 15-40 ppm in accordance with $\mathrm{WHO}$ recommendations. At the national level, $74.3 \%$ of participants had optimal iodine nutrition compared to $77 \%$ reported in the 1994-1995 survey (9). Both surveys reported the lowest UIC level in the southern region.
In the present study, there was a considerable improvement in iodine nutritional status in the southern region, as demonstrated by the reduction in the proportion of participants with median $\mathrm{UIC}<50 \mu \mathrm{g} / \mathrm{L}$ and $50-99 \mu \mathrm{g} / \mathrm{L}$ from $18.0 \%$ and $27 \%$ to $6.4 \%$ and $17.9 \%$ respectively. This suggests a marked effect of the USI strategy in that vulnerable locality. A study conducted in Jizan in the southern region among 311 children aged 6-13 years, in 2010 reported a high level of UIC $(421 \mu \mathrm{g} / \mathrm{L})(13)$. Such a high value was not seen in the present study. A further investigation and periodic monitoring should be considered.

A significant inverse relationship $(\mathrm{OR}=0.39 ; P<0.001)$ was recognized between UIC and goitre prevalence, consistent with other studies $(9,25)$. No significant gender difference in median UIC was found in the present study compared to a higher value among male participants in the first national survey (9).

\section{Salt iodization}

Worldwide, salt iodization is accepted as a safe, cost-effective and sustainable strategy to ensure sufficient intake of iodine (7). The present work demonstrated a higher UIC and lower goitre prevalence among children of households consuming iodized salt, which indicates the contribution of iodized salt prophylaxis to prevention of IDD, as established in international studies (8).

Studies of household consumption of iodized salt in Saudi Arabia are scarce. A report from Hail in northern Saudi Arabia in 2004 described the pattern of household salt consumption and pointed to the prevalent pattern of consumption of noniodized salt in that area. Only $27.7 \%$ of households were consuming iodized salt as an exclusive source of salt, $31.6 \%$ were consuming noniodized salt and $40.7 \%$ were consuming iodized salt as a table salt and not for cooking purposes (12). In contrast, a study in Jizan in south-western Saudi Arabia in 2010 reported that almost all households were consuming iodized salt (13).
At the national level, the present survey revealed that $69.8 \%$ of households were consuming adequately iodized salt, however, noniodized salt is still available in the markets and preferred by many households in some regions. The lowest rate of households consuming iodized salt was found in the northern region (53.8\%), and the highest rate was in the western region (80.6\%). No regional or sub-regional locality attained the WHO/UNICEF/ ICCIDD criterion of $>90 \%$ of households consuming adequately iodized salt (2). The marked variations among regions imply the need to study factors affecting such disparities and preferences of households with regard to salt consumption.

The iodine content of iodized salt measured by iodometric titration revealed a mean of $50.4 \pm 21.8 \mathrm{ppm}$ and median of 51 ppm that was higher than the recommended level (15-40 ppm). This draws attention to the need for a good monitoring system to ensure commitment and proper quality control systems of salt producers. As a result of nonmandatory regulation, several salt producers still fortify salt according to the previous code (70-100 ppm). It is essential to change legislation to mandate the iodine salt adjustment (15-40 $\mathrm{ppm}$ ) instead of just recommending it.

In other countries in the region, the proportion of households consuming iodized salt was $11.0 \%, 29.5 \%, 68.5 \%$, 78.7, 88.3\% and 92.0\% in Sudan, Yemen, Oman, Egypt, Jordan and Lebanon respectively (26).

\section{Study limitations}

Our study had some limitations. In spite of good training to assure inter-rater agreement, clinical assessment of goitre by many physicians is still liable to variations. Application of more reliable sonography for goitre assessment will be considered in future surveys. Difficulties in recruiting the ideal number of children in some clusters in Jizan in the southern region were encountered 
because of high absenteeism during the survey period as a result of heavy rain. Another problem regard goitre examination was encountered in Hail in the northern region, where an exceptionally high goitre prevalence was recorded compared with all other clusters in the northern region; this needs confirmation to exclude any observer bias. However, these limitations did not compromise the results because of their limited population weight. A local confirmatory survey will be arranged in Hail and Jizan.

\section{Conclusion}

Our findings suggest that Saudi Arabia is iodine sufficient at the national level, however the southern region still has goitre with a mild degree of severity. The proportion of households consuming adequately iodized salt is still below WHO/ ICCIDD/UNICEF recommendations. There is a need to strengthen the legislation to ban the sale of noniodized salt and to launch public health awareness programmes. The government is advised to establish a proper surveillance system for monitoring sustainability.
Acknowledgements

We would like to thank all those who facilitated this study at the Ministry of Health and Ministry of Education, participating staff of the General Administration of Laboratories and Blood Banks and staff members of the Directorate General of Nutrition. Special thanks are due to all medical staff who actively participated in the field work.

\section{Funding: None.}

Competing interests: None declared.

\section{References}

1. Zimmermann MB. The role of iodine in human growth and development. Semin Cell Dev Biol. 2011 Aug;22(6):645-52.

2. World Health Organization/United Nations Children's Fund/ International Council for the Control of Iodine Deficiency Disorders. Assessment of iodine deficiency disorders and monitoring their elimination. 3rd ed. Geneva: World Health Organization; 2007.

3. The world health report 2002. Reducing risks, promoting healthy life. Geneva: WHO; 2002.

4. Bath SC, Steer CD, Golding J, Emmett P, Rayman MP. Effect of inadequate iodine status in UK pregnant women on cognitive outcomes in their children: results fro---m the Avon Longitudinal Study of Parents and Children (ALSPAC). Lancet. 2013 Jul 27;382(9889):331-7. PMID:23706508

5. Andersson $M$, Karumbunathan V, Zimmermann MB. Global iodine status in 2011 and trends over the past decade. J Nutr. 2012 Apr;142(4):744-50. PMID:22378324

6. Zimmermann MB. Symposium on 'Geographical and geological influences on nutrition': lodine deficiency in industrialised countries. Proc Nutr Soc. 2010 Feb;69(1):133-43. PMID:19968908

7. United Nations Children's Fund-World Health Organization Joint Committee on Health Policy. World summit for children - mid decade goal: iodine deficiency disorders (JCHPSS/94/2.7). Geneva: United Nations Children's Fund, World Health Organization; 1994 (http://www.ceecis.org/ iodine/01_global/01_pl/01_01_1994_summit.pdf, accessed 1 May 2016).

8. Fortification of food-grade salt with iodine for the prevention and control of iodine deficiency disorders. Geneva: World Health Organization; 2014

9. Al-Nuim A, Kamel Farag M, Al-Mazrou Y, Al-Attas O. National iodine deficiency disorders survey - Saudi Arabia, 1994-1995. Riyadh: Ministry of Health; 1995.

10. Al-Nuaim AR, Al-Mazrou Y, Kamel M, Al-Attas O, Al-Daghari N, Sulimani R. lodine deficiency in Saudi Arabia. Ann Saudi Med. 1997 May;17(3):293-7. PMID:17369725

11. Gulf Cooperation Council Standardization Organization. GSO 1843: food grade salt; 2010.

12. Haridi HK, Al-Taieb AA, Al-Haraka EA, Al-Mezaini SM, AlHosary MM, Mousa AS, et al. Project Early Detection \& Health Education of Thyroid Cancer in Hail, 2004. Hail, General
Directorate of Health Affairs; 2005 (unpublished report, Ref $3607 / 1 / 43)$.

13. Alsanosy RM, Gaffar AM, Khalafalla HE, Mahfouz MS, Zaid AN, Bani IA. Current iodine nutrition status and progress toward elimination of iodine deficiency disorders in Jazan, Saudi Arabia. BMC Public Health. 201211 20;12:1006. PMID:23167286

14. Central Department of Statistics \& Information. KSA. General Census of Population and Housing, 2010 (http://www.cdsi. gov.sa/english/index.php?option=com_docman\&task=cat_ vie, accessed 19 September 2014).

15. World Health Organization/United Nations Children's Fund/ International Council for Control of Iodine Deficiency Disorders. Elimination of iodine deficiency disorders: a manual for health workers. Cairo: WHO Regional Office for Eastern Mediterranean; 2008.

16. General Department for Planning and Statistics. [Statistical summary report for male and female education 1429-1430 H]. Riyadh: Ministry of Education; 2009. [in Arabic].

17. Abu-Eshy SA, Abolfotouh MA, Al-Naggar YM. Endemic goitre in schoolchildren in high and low altitude areas of Asir region, Saudi Arabia. Saudi Med J. 2001 Feb;22(2):146-9. PMID:11299410

18. Dunn JT, Crutchfield HE, Gutekunst R, Dunn AD, Bourdoux P, Gaitan $\mathrm{E}$ et al. Methods for measuring iodine in urine. Amsterdam: International Council for Control of Iodine Deficiency Disorders; 1993.

19. Al-Attas OS, Solimani RA. Iodine concentration in Saudi staple food. Saudi Med J. 1993;14:322-4.

20. Johnson CC, Fordyce FM, Stewart AG. Environmental controls in iodine deficiency disorders. Project summary report. British Geological Survey commissioned report CR/03/058N. Nottingham: British Geological Survey; 2003 (http://nora.nerc. ac.uk/8355/1/CR03058N.pdf, accessed 1 May 2016).

21. Stubbe $\mathrm{P}, \mathrm{Al}$ Habib $\mathrm{S}$, Thal $\mathrm{H}$. lodine excretion and goiter prevalence in Saudi Arabian children. Saudi Med J. 1988;9:476-80.

22. Delange F. The disorders induced by iodine deficiency. Thyroid. 1994 Spring;4(1):107-28. PMID:8054857

23. Kaloumenou I, Alevizaki M, Ladopoulos C, Antoniou A, Duntas $\mathrm{LH}$, Mastorakos G, et al. Thyroid volume and echostructure in schoolchildren living in an iodine-replete area: relation to age, pubertal stage, and body mass index. Thyroid. 2007 Sep;17(9):875-81. PMID:17956161 
24. Global Scorecard. Network for sustainable elimination of iodine deficiency. New York: UNICEF; 2010.

25. Delange F, Benker G, Caron P, Eber O, Ott W, Peter F, et al. Thyroid volume and urinary iodine in European schoolchildren: standardization of values for assessment of iodine deficiency. Eur J Endocrinol. 1997 Feb;136(2):180-7. PMID:9116913
26. International Council for the Control of lodine Deficiency Disorders. Global lodine Nutrition Scorecard for 2012 (http://iccidd.org/cm_data/Scorecard_ICCIDD_website_18_12_2012. pdf, accessed 1 May 2016). 